\title{
The Impact of Online Disinformation on Democracy in Taiwan
}

\author{
Julian Neylan \\ Leiden University \\ julian.neylan@gmail.com
}

\begin{abstract}
Is online disinformation impacting how voters view political parties? Although many scholars claim that online disinformation (or fake news) is having negative effects on democracy, there are few studies that examine the impact of online disinformation at the individual level. In this study I conducted a randomized survey of 400 Taiwanese respondents in order to assess the impact of online disinformation on their political behavior. The respondents completed one of three surveys and were exposed to either a control article or a social media post containing disinformation. Controlled exposure was found to have a significant impact on the party identification of those exposed to the post for the first time compared to those who had previously been exposed to the post. The results of this study show that disinformation can have an effect on party identification, however further studies are necessary to determine the size and direction of this effect.
\end{abstract}

\section{Introduction}

Online disinformation campaigns have been used by governments, militaries, political parties and private citizens to manipulate public opinion in 70 countries, many of which are democracies [1]. Politicians, pundits, and scholars have all made dire claims about how online disinformation is eroding the fabric of modern democracy $[2,1]$. They argue that a public whose worldviews are formulated based on false information will not be able to select candidates that represent their interests [3]. However, much of the concern surrounding online disinformation is not backed by solid evidence. Studies attempting to examine the impact of online disinformation have found wildly different results, yet none absolutely confirm that online disinformation is harming democracy [4]. Attempts to combat online disinformation have led to extreme measures in some countries including internet shutdowns and laws that restrict free speech [5].

Taiwan is at the epicenter of the debate over how a government should respond to online disinformation. Online disinformation in Taiwan is generated both internally and from mainland China. In response, the Democratic People's Party (DPP) passed an anti-infiltration law that is designed to combat interference from mainland China [6]. However, proponents of press freedom strongly opposed the bill believing that it would obstruct free speech in Taiwan [6]. It is necessary to assess the impact of online disinformation on political views as political actors are enacting legislation against a phenomenon that so far has not been empirically demonstrated to alter elections.

In this study I analyze the impact of online disinformation on Taiwanese voter's political identification. Disinformation is designed with the intention of spreading false beliefs while misinformation is false information that is spread regardless of intention [7]. This study focuses only on disinformation as it allows actors to potentially alter democracy in a way misinformation does not. Disinformation is created with the intention of destroying the public's understanding of reality while misinformation can be an honest misinterpretation of the facts. In the broader literature disinformation is often termed fake news, however I use the term disinformation as it has only one meaning while fake news can be a genre (pseudo-journalistic disinformation) as well as a label (used to delegitimize news media) [8].Within the scope of this study I analyze how exposure to online disinformation impacts party identification.

The existing literature on online disinformation primarily focuses on the United States and Europe. Fewer studies outside of these contexts have looked at the impacts of online disinformation. My study is the first of its kind in Taiwan, however it is theoretically linked to studies elsewhere in the world and contributes to the broader literature. Using survey data from 400 random respondents in Taiwan I analyzed the impact of controlled exposure to online disinformation on party identification. After exposure respondents completed an extensive debrief. Exposure to online disinformation was found to impact party identification for first time viewers relative to those already exposed. 


\section{Hypotheses}

Once someone sees a false article, one would assume that its positive or negative portrayal of a political party would cause that individual to have an equivalent response towards said political party. However, studies have revealed that polarization can interfere with people's reception and understanding of information. For this study I used Guess et al.'s [9] definition of polarization as the difference in people's feelings toward their preferred party and the opposition party. Studies have shown that partisanship can bias information processing in the brain, and even people's perceptual judgements of content [10]. Political psychology research has shown that partisanship and ideology form over a long period of time due to a wide variety of mechanisms [11]. This slow formation of ideology makes it so that it is difficult for new information to change people's longstanding views.

Psychological research shows that partisans are often "directionally motivated", meaning they seek out information that reinforces their preferences rather than accurate information [12]. Even if people are confronted with facts that counter their preconceived beliefs, they still may not be convinced by them [10]. This effect is similar for online disinformation in that people will reinforce their preexisting beliefs with false articles. Studies in the U.S. looking into polarization have found that online disinformation does not impact voters' feelings towards political parties [9]. Information received by those who are already highly partisan is unlikely to alter their preconceived beliefs [13]. Taiwan is a good case to test whether the studies on online disinformation's impact on polarization conducted in the U.S. are transferable to other parts of the world.

Taiwan is in many ways similar to the U.S. in having: a polarized electorate, a similar internet penetration rate, and is subjected to online disinformation campaigns from both foreign and internal actors. The similarity of polarization will allow for a test of the echo chamber theory outside of the U.S. The echo chamber theory is often applied to Taiwan, despite it being a relatively young democracy, as it is highly polarized $[14,15]$. The echo chamber theory asserts that online communities disaffected by mainstream media share information that goes unchallenged and these communities become more partisan as they reinforce each other's views [16]. The main area in which polarization differs between the U.S. and Taiwan is that the primary point of contention in Taiwan surrounds its relationship with mainland China [17]. Proponents of the Kuomintang party (KMT) would like closer ties with mainland China, while the DPP does not. This study tests if online disinformation can impact polarization, when the difference between parties is not "left" or "right" but rather relates to Taiwan's relationship with mainland China. Taiwan is highly partisan, so online disinformation once seen is still unlikely to alter respondents' perceptions of political parties.

\section{H1: Online disinformation will not impact respondents' reported polarization among partisans; party identification will not be impacted by disinformation.}

\section{Methodology}

To test the hypotheses, I developed a survey and posted it on Facebook from April $17^{\text {th }}$ to April $28^{\text {th }}, 2020$. I posted a Facebook advertisement with a link to the survey. Respondents were told that the survey was designed to assess the effects of media on politics in Taiwan. The respondents were incentivized with a randomly distributed $\$ 20$ raffle prize for three respondents. The advertisement targeted the entirety of Taiwan and in total I received 400 completed surveys. This is a convenience sample composed of people who decided to take the survey. This paper is primarily designed to develop theory; therefore, a convenience sample is preferred as this allows me to verify an existence result: whether or not online disinformation has an impact [18]. If there is an effect, later studies with representative samples can establish the external validity of online disinformation's impact on the Taiwanese electorate.

The survey gathered respondents' demographic information including age, gender, education, and location. I also asked for their history of sharing news on Facebook, party identification, media trust and perceived accuracy of the post, as these might be explanatory factors for how people perceive online disinformation. To measure the respondents' intention to vote, I asked about their voting history and plan to vote in the next election. There were 15 partially completed responses. Only survey respondents that had completed all four parts of the survey were included in the analyses which totaled 400 valid responses.

Taiwan has five different political parties that hold national representative positions in the legislative yuan, however only two, The DPP and the KMT hold the vast majority of seats. The anti-KMT post shows a photograph from a China unification parade of people waving Republic of China and 
Chinese Communist Party flags and mistakenly says that this photo was taken at the Ting Han parade, which was in support of the KMT's presidential candidate Han Kuo-yu [19]. The text says that if the KMT candidate is elected it will be the end of Taiwan, insinuating that the KMT candidate will allow for unification with mainland China, which is highly unpopular among Taiwanese people [19]. The anti-DPP post asserts that the DPP wants to pass legislation that radically increases sentencing leniency towards drug possession on school campuses [20]. The control article is about a professional video game player who is speculated to be leaving his team soon [21]. The control is apolitical so that differences in stated party identification in the experimental groups solely reflect the effect of online disinformation. A control allows us to see if the survey design is conducive to producing consistent responses between the pre- and post-exposure portions and allows for a comparison between political and apolitical content. The video game player mentioned in the control does not have well publicized political views, and the video game is played worldwide and isn't associated with any political entity. Ideally, there would have been a pure control with exposure to no article, however with 400 respondents it is unlikely that statistical analysis with two separate controls would yield any significant results.

I analyzed pre- and post-exposure selfreported party identification with four political parties: KMT, DPP, New Power Party (NPP), and People First Party (PFP). The inclusion of two additional parties, the NPP and PFP, allow for a check of whether exposure to disinformation can affect party identification with non-directly targeted parties.

Partisan identification is difficult to alter as researchers studying campaigns generally have contested whether any information impacts voter behavior. Research on campaigns has found that the core values of voters are unlikely to change based on material presented, but that some information can impact vote choice as voters become better informed about candidates [13]. The effect of information is often quite small, Spenkuch \& Toniatti [22] found that television advertisements were found to change the voting preferences of only 1-3 people out of 10,000 .

Respondents were randomly exposed to an anti-DPP post, an anti-KMT post, or a control article. Once the survey was completed there was an extensive debrief. The respondents of the experimental groups were told that the post they had seen was false. Respondents were given an explanation of why the post was false from the Taiwan Fact Check Center. The respondents were then asked if they understood that the post was false and asked to select the correct name of the fact check center.

To test the hypothesis, I constructed a dependent variable that's takes the value of 1 if party identification changed from pre-exposure to postexposure for the DPP or KMT. Respondents answered on a 4-point Likert scale how closely they identified with each of the major parties in Taiwan before and after exposure to the post. For most respondents there was no change in identification. The identification of the majority of respondents did not change over the course of the survey: $87 \%$ of respondents had no change in identification towards the KMT or DPP, while $13 \%$ had changes in identification for these two parties. $22.75 \%$ of respondents had changes in party identification when considering all four parties, while $77.25 \%$ had no changes in party identification. I ran an additional regression with a value of 1 if party identification changed for any party pre- and post-exposure.

The age range of the respondents was 18 to 77 , however the respondents tended to be younger, with $60 \%$ under the age of 30 . Gender was divided between male and female at $48.5 \%$ and $50.5 \%$ respectively and $.5 \%$ identified as other. $59.5 \%$ of respondents were college educated. $74.9 \%$ of respondents were from urban areas. The most skewed demographic was the party identification category, where $38.4 \%$ identified with the DPP while only $4 \%$ identified with the KMT; the rest were either independent, other, or identified with another party. For a full list of descriptive statistics see the appendix.

\section{Who is swayed by disinformation?}

I regressed whether there was a change in identification for the DPP or KMT on exposure to disinformation while controlling for education, party affiliation, perceived accuracy of the story, level of media trust, and previous exposure to the post. I included an interaction effect between previous exposure to the post and party affiliation. Education [23], party affiliation [13], and media trust [16, 23] have all been theorized to be contributing factors in how online disinformation is received. For party affiliation the reference category is independent, so all changes in identification are relative to those who identify as independent. Enough respondents identified with the DPP that it could be its own variable, while there were not enough respondents for 
each of the other parties to be their own variables. The variable of 'other parties' includes those who identify with the KMT, PFP, NPP and those who selected 'other party'. For education, college is the reference category. For the two experimental groups 'anti-DPP post' and 'anti-KMT post' the control is the reference category.

I included the independent variable of 'accuracy' because the impact of how accurate the post was perceived to be on changes in party identification is underexamined. Guess et al. [9] found that belief in false articles was not correlated with changes in voters' feelings towards political parties. However, it is intuitive to believe that posts which negatively portray a party, if believed, would alter a respondent's views towards that political party, therefore this experiment allows for a test of Guess et al.'s [9] findings. For the accuracy variable, those who said the post was inaccurate constitute the reference category.

I also included interaction effects for those who had already seen either post before, to determine what the difference is between first time exposure and repeated exposures. 230 of the respondents had not previously seen the posts while 170 had already seen the posts. Within the experimental groups, $41 \%$ of the anti-DPP group and 59\% of the anti-KMT group had already seen the post. I included interaction effects for party identification and exposure to the post in order see how partisanship effected first time viewers versus those already exposed.

The results showed that the effect of the posts was largely insignificant for both experimental groups. In the first model there appears to be no significant impact of exposure to online disinformation. Once the interaction effect is included and the groups are divided by whether the respondent had previously seen the post, the effects of exposure were significant. Those who had not seen the post previously were more likely to have their party identification changed than those who had previously seen the post. This suggests that exposure to the post for the first time did impact respondents' party identification with the KMT or DPP. Those who had seen the post before, likely in a normal social media environment, were significantly less likely to have their identification changed. This may be because they have already seen the post debunked by a fact checking website, or because they have previously processed the content of the post, so the post did not have an additional effect.

Model 3 shows that those who identified with the DPP were significantly less likely than independents to change their opinion, however model 4 shows that regardless of party affiliation exposure to disinformation had no significant impact on changing party identification. Model 3 and 4 show that education level, perceived accuracy of the story and amount of trust in the media did not have significant effects on whether the respondents' party identification changed. Education had previously been linked to an increased ability to discern the veracity of news [24]. However, the ability to accurately determine if a post was true did not seem to have a significant effect on whether the respondent changed their party identification. The level of trust in the media had an insignificant impact on whether people changed their opinion. Online disinformation has been shown to lower media trust, but it did not appear that this decreased media trust was correlated with increased susceptibility to changing party identification [25]. 
Table 1. Logistic regression of change in party identification for the DPP and KMT

\begin{tabular}{|c|c|c|c|c|}
\hline & Model 1 & Model 2 & Model 3 & Model 4 \\
\hline (Constant) & $-2.106 * * *(.283)$ & $-2.442 * * *(.369)$ & $-1.567 *(.776)$ & $-1.349(.821)$ \\
\hline Anti-KMT post & $.168(.384)$ & $1.103 *(.501)$ & $1.195 *(.514)$ & $.583(.717)$ \\
\hline Anti-DPP post & $.405(.369)$ & $.938 *(.472)$ & $1.172 *(.503)$ & $.991(.629)$ \\
\hline High school or less & & & $-.421(.607)$ & $-.390(.611)$ \\
\hline Post grad & & & $-.453(.356)$ & $-.461(.362)$ \\
\hline DPP & & & $-1.342 * * *(.404)$ & $-2.547 *(1.093)$ \\
\hline Other parties & & & $-.358(.371)$ & $-.511(.703)$ \\
\hline Accuracy & & & $.630(.385)$ & $.624(.396)$ \\
\hline Media trust & & & $-.143(.216)$ & $-.137(.217)$ \\
\hline Anti-KMT $x$ have seen & & $-2.298 * *(.800)$ & $-2.235 * *(.831)$ & $-2.239 * *(.846)$ \\
\hline Anti-DPP $\mathrm{x}$ have seen & & $-1.600 *(.772)$ & $-1.675 *(.800)$ & $-1.609 *(.819)$ \\
\hline Have seen post & & $1.099(.588)$ & $1.014(.607)$ & $.968(.634)$ \\
\hline Anti-KMT x DPP & & & & $1.790(1.289)$ \\
\hline Anti-DPP x DPP & & & & $1.354(1.243)$ \\
\hline $\begin{array}{l}\text { Anti-KMT } \mathrm{x} \text { other } \\
\text { party }\end{array}$ & & & & $-.181(.921)$ \\
\hline Anti-DPP $\mathrm{x}$ other party & & & & $.766(.960)$ \\
\hline$-2 \mathrm{LL}$ & 307.855 & 298.380 & 283.953 & 280.255 \\
\hline $\begin{array}{l}\text { Cox and Snell's R } \\
\text { squared }\end{array}$ & .003 & .026 & .060 & .069 \\
\hline $\begin{array}{l}\text { Nagelkerke's R } \\
\text { squared }\end{array}$ & .006 & .049 & .112 & .128 \\
\hline $\mathrm{N}$ & 400 & 400 & 399 & 399 \\
\hline
\end{tabular}

Additionally, I regressed whether there was a change in identification for all four parties on exposure to disinformation while controlling for education, party affiliation, perceived accuracy of the story, change in media trust, and previous exposure to the disinformation. This regression had increased statistical power as 52 respondents had changes in identification for the KMT or DPP, while 91 had changes in identification for all four parties. The results were similar to the previous regression however the interaction variable was not significant. This suggests that previous exposure to the post had less of an impact on identification changes for other parties than those directly mentioned in the posts.

\subsection{Note on identification changes:}

The changes in identification were not consistently negative as one would expect. Both of the experimental posts had negative content against a party and should have caused people to have more negative views of the parties. However, it may be the case that for those whose party was attacked by the post, their identification with their party increased as they sympathized with their party in the face of the inflammatory disinformation put out by the opposition. Negative campaigning has been shown to lead to a backlash effect, where the attacking party is evaluated lower [26]. This backlash effect can also positively impact parties who are neither the target of the attack nor the attacker [27]. Table 2 shows that change in party identification were comparable between the KMT and DPP and the other two parties. 
Table 2. Change in party identification by exposure group

\begin{tabular}{lllllll} 
& $\begin{array}{l}\text { Positive } \\
\text { change } \\
\text { KMT }\end{array}$ & $\begin{array}{l}\text { Negative } \\
\text { change } \\
\text { KMT }\end{array}$ & $\begin{array}{l}\text { Positive } \\
\text { Change DPP }\end{array}$ & $\begin{array}{l}\text { Negative } \\
\text { Change } \\
\text { DPP }\end{array}$ & $\begin{array}{l}\text { Positive } \\
\text { change all four } \\
\text { parties }\end{array}$ & $\begin{array}{l}\text { Negative } \\
\text { Change all four } \\
\text { parties }\end{array}$ \\
\hline $\begin{array}{l}\text { Control } \\
\text { Anti-KMT }\end{array}$ & 6 & 5 & 4 & 5 & 15 & 22 \\
$\begin{array}{l}\text { post } \\
\text { Anti-DPP }\end{array}$ & 5 & 2 & 6 & 6 & 21 & 21 \\
post & 5 & 5 & 7 & 9 & 31 & 23
\end{tabular}

\section{Discussion}

The results indicate that those who identified with a party were not significantly impacted by exposure to disinformation. This is in line with Jacobson's [13] finding that highly partisan people are unlikely to change their opinions based on new information. This confirms the hypothesis that online disinformation did not impact partisan respondents' reported polarization.

However, independents were similarly not impacted by exposure to disinformation. This suggests that partisanship is not the only reason why a post might not change the opinions of a respondent. Independents are still somewhat partisan as studies in the U.S. have found that many independents do have partisan preferences [28]. These results suggest that future research should examine aspects beyond the impact of partisanship when assessing the impact of disinformation.

Despite the overall lack of change in opinion due to disinformation, it appears that disinformation still may have an effect. There was a significant change in party identification between those who had seen the story before and those who had not. This suggests that the post only impacted first-time viewers. Additionally, having seen the post may mean that the respondent is more likely to regularly consume disinformation. Guess et al. [9] found that those who consume more disinformation tend to have more polarized feelings towards political parties. Therefore, the decrease in the likelihood of these respondents to change their identification with political parties may be due to increased polarization of this demographic rather than the impact of the article. However, this study did not capture enough information about respondents' disinformation or general media consumption to confirm whether these results reflect the impact of first-time exposure, or the characteristics of those who regularly consume disinformation.
To confirm the results of this study more robust studies need to be conducted. The effect of disinformation may be quite small and undetectable in a group of 400 respondents. Given that the majority of those sampled had no change in opinion and that the changes in opinion were divided into three exposure groups, the binary logistic regressions were based on relatively small sample sizes. Small sample sizes can lead to false discoveries [29]. Further studies with larger samples are necessary to confirm these results, especially to obtain results that are externally valid for Taiwan as a whole.

Additionally, there are no medium to long term studies on the effects of disinformation [7]. This study only examined brief exposure to disinformation and future studies which examine long term effects are necessary.

Additionally, this study was unable to factor in all of the contributing factors that determine political ideology. There are nearly innumerable factors that can contribute to ideological viewpoints, from socio-economic status [30] communal beliefs [31], personality traits [32], to even basic neurocognitive functioning [33]. Future studies will need to look at what other factors contributing to party identification are also linked to susceptibility of being influenced by online disinformation.

The changes in party identification were not only negative as predicted but rather both positive and negative. The impact of online disinformation cannot be easily predicted, and may have a negative or positive impacts on party identification, consistent with the findings of Galasso et al. [27]. This study also shows that disinformation can change party identification, including for parties that are not directly attacked. Spillover effects of negative advertisements are currently underexplored in the literature, and further studies are needed to theorize why we observe this phenomenon.

This study found that the majority of respondents did not have changes in party 
identification, which may be due to them either ignoring the disinformation or because disinformation reinforced their current views. This study did not find a significant difference between independents and partisans when exposed to disinformation which would contradict the echo chamber theory. Additionally, the level of media trust was insignificant in whether people changed party identification or not. This suggests that counter to the echo chamber theory, people who were less trusting of mass media were not more susceptible to having their views altered by disinformation. The inapplicability of the echo chamber theory may be due to differences between the Taiwanese online media environment versus those in western settings. However, this study was also unable to act as a full test of the echo chamber theory. To properly test the echo chamber theory, it is necessary to understand the totality of a respondent's media consumption. Exposure to an individual post may have a limited effect, but when online disinformation makes up a more significant amount of an individual's media consumption, there may be a more substantial impact. Ideally, to test the change in polarization the sample would have been more representative of the various parties. In this sample the DPP was well represented while the KMT had relatively few supporters. This made it difficult to accurately measure changes in polarization.

The effect of online disinformation is contingent upon the content of post shown. The antiKMT post, was seven times more likely to be perceived as accurate by respondents than the antiDPP post. Therefore, the content of disinformation is highly important when evaluating the effect of disinformation. This study mirrored many contemporary studies in assuming that the effect of different pieces of disinformation would be similar. Ideally in future tests there would be a space for respondents to fill in their opinion of each post, so that there can be a qualitative assessment of why certain posts are perceived to be more accurate. Future tests will need to take the unequal effects of different posts into consideration when assessing the impact of exposure to online disinformation. This study also showed that despite the differences in perceived accuracy of the stories, the difference between first time exposure to the article and previous exposure was still present. This suggests that the perceived accuracy of the post may not be what changed respondents party identification.

Additionally, this study only takes into account exposure in a controlled setting. Previous work has shown that exposure to online disinformation in controlled and natural settings can have different effects [9]. Future studies should also incorporate the impact of interpersonal communication that social media allows. The twostep theory of communication purports that individuals are far more likely to change their opinion based on interpersonal interactions than from mass media outlets [34]. Social media allows for mass interpersonal communication, and disinformation may be most effective when it is delivered from interpersonal contacts rather than in a survey [35]. Additionally, the fact that the level of trust in media was inconsequential in whether people changed their identification supports the two-step flows of communication theory in suggesting that respondents were not receptible to media alone, but may need an opinion leader or interpersonal interaction to influence them.

Moreover, this experiment featured no pure control. Although the news article presented in the control was not related to politics, respondents still changed their party identification after exposure. There may have been political biases present in the article that I was unaware of. The changes in party identification suggest either that the article had an effect or that some respondents provided careless answers. Previous studies have shown that up to 10$12 \%$ of responses to a survey may be done carelessly [36].

One takeaway from this study is that future studies need to be cautious with debriefs after exposure to disinformation. After the debrief, the group exposed to the anti-DPP article had 8 respondents who selected that they did not understand that the story was false. For the anti-KMT article, 25 people did not understand that the article was false. The debrief explained to respondents why the article was false, however it appears that many respondents disagreed or did not properly complete the debrief. The majority of those who did not understand that the post was false had previously seen the post before, suggesting that they had already regarded the post as fact and could not be dissuaded from this view. This is concerning as the methodology of exposing people to disinformation has been used in other studies, including medical information about COVID-19 [9, 37]. Future studies need to be aware of the potential dangers of exposing respondents to disinformation and need to collect data on the effectiveness of their debriefs.

These results have ramifications not only for Taiwan, but for democracies impacted by disinformation across the world. A future study determining the size of the effect of disinformation 
on changes in political identification, and how people respond to online disinformation in a normal media environment, is necessary to further assess the impact of false stories. Online disinformation is not harmless however there is also a cost to combating it. Disinformation is often indistinguishable from satire and curbing disinformation can also curb free speech. In order to properly decide what measures should be taken against disinformation, more studies are necessary to examine who is affected and what the size of this impact.

\section{References:}

[1]

S. Bradshaw and P. N. Howard, "The Global Disinformation Order 2019 Global Inventory of Organised Social Media Manipulation," University of Oxford, Oxford, 2019.

N. Aspinwall, "Taiwan's War on Fake News Is Hitting the Wrong Targets," Foreign Policy, 10012020 .

[7] D. M. J. Lazer, M. A. Baum, Y. Benkler, A. J. Berinsky, K. M. Greenhill, F. Menczer, M. J. Metzger, B. Nyhan, G. Pennycook, D.

Rothschild, M. Schudson, S. A. Sloman, C. R. Sunstein, E. A. Thorson, D. J. Watts and J. L.
Zittrain, "The science of fake news," Science, pp. 1094-1096, 2018.

[8] J. L. Egelhofer and S. Lecheler, "Fake news as a two-dimensional phenomenon: a framework and research agenda," Annals of the

International Communication Association, pp. 97-116, 2019.

[9] A. M. Guess, D. Lockett, B. Lyons, J. M. Montgomery, B. Nyhan and J. Reifler, "“Fake news" may have limited effects beyond increasing beliefs in false claims," The Harvard Kennedy School Misinformation Review, pp. 1-12, 2020.

[10] J. J. V. Bavel and A. Pereira, "The Partisan Brain: An Identity-Based Model of Political Belief," Trends in Cognitive Sciences, pp. 213224, 2018.

[11] Neve, Jan-Emmanuel. D. (2013). Personality, Childhood Experience, and Political Ideology. Political Psychology, 55-73.

[12] D. Flynn, B. Nyhan and J. Reifler, "The Nature and Origins of Misperceptions: Understanding False and Unsupported Beliefs About Politics," Advances in Political Psychology, pp. 127-150, 2017.

[13] G. C. Jacobson, "How Do Campaigns Matter?," Annual Review of Political Science, pp. 31-47, 2015.

[14] F. H. Calderon, L.-K. Cheng, M.-J. Lin, Y.-H. Huang and Y.-S. Chen, "Content-Based Echo Chamber Detection on Social media platforms," in 2019 IEEE/ACM International Conference on Advances in Social Networks Analysis and Mining, Vancouver, 2019.

[15] C. Clark and A. C. Tan, "Political Polarization in Taiwan: A Growing Challenge to Catch-all Parties?," Journal of Current Chinese Affairs, pp. 7-31, 2012.

[16] C. R. Sunstein, \#Republic, Princeton: Princeton University Press, 2017.

[17] C. H. Achen and T. Y. Wang, "The Taiwan Voter: An Introduction," in The Taiwan Voter, Ann Arbor, University of Michigan Press, 2017, pp. 125.

[18] R. B. Morton and K. C. Williams, Experimental Political Science and the Study of Causality: From 
Nature to the Lab, 2010: Cambridge University Press, 2010.

[19] Taiwan Fact Check Center, "網傳照片「挺韓遊 行竟然手拿五星旗」? ," 0701 2020. [Online]. Available: https://tfc-taiwan.org.tw/articles/1892.

[20] Taiwan Fact Check Center, "Fact Check Report," 2512 2019. [Online]. Available: https://tfctaiwan.org.tw/articles/1670.

[21] Newtalk, "《英雄聯盟》前世界冠軍「被」分 手? CLG 戰隊與 Crown 終止合約," 432020. [Online]. Available: https://tw.news.yahoo.com/\%E8\%8B\%B1\%E9\%9 B\%84\%E8\%81\%AF\%E7\%9B\%9F-\%E5\%89\%8D $\% \mathrm{E} 4 \% \mathrm{~B} 8 \% 96 \% \mathrm{E} 7 \% 95 \% 8 \mathrm{C} \% \mathrm{E} 5 \% 86 \% \mathrm{~A} 0 \% \mathrm{E} 8 \%$ BB\%8D-\%E8\%A2\%AB-\%E5\%88\%86\%E6\%89 $\% 8 \mathrm{~B}-$ clg\%E6\%88\%B0\%Е9\%9A\%8A\%Е8\%88\%87cro wn\%E7\%B5\%82\%E6\%AD\%A2\%E5\%90\%88\%E 7\%B4\%84-034225320.html.

[22] Spenkuch, J. L., \& Toniatti, D. (2018). Political Advertising and Election Results. The Quarterly Journal of Economics, 1981-2036.

[23] Pariser, E. (2011). The filter bubble: What the Internet is hiding from you. Penguin UK.

[24] H. Allcott and M. Gentzkow, "Social Media and Fake News in the 2016 Election," Journal of Economic Perspectives, pp. 211-236, 2017.

[25] H. Wasserman and D. Madrid-Morales, "New data suggests African audiences see significantly more misinformation than Americans do," 2611 2018. [Online]. Available: https://www.niemanlab.org/2018/11/new-datasuggests-african-audiences-see-significantlymore-misinformation-than-americans-do/.

[26] M. Haselmayer, "Negative campaigning and its consequences: a review and a look ahead," French Politics, pp. 355-372, 2019.

[27] V. Galasso, T. Nannicini and S. Nunnari, "Positive Spillovers from Negative Campaigning," University of Lugano Center for Economic Policy Research, Lugano, 2020.

[28] S. Klar and Y. Krupnikov, Independent Politics: How American Disdain for Parties Leads to Political Inaction, Cambridge: Cambridge University Press, 2016.

[29] W. Forstmeier, E.-J. Wagenmakers and T. H. Parker, "Detecting and avoiding likely falsepositive findings - a practical guide," Biological Reviews, pp. 1941-1968, 2016.

[30] Bakker, B. N. (2016). Personality Traits, Income, and Economic Ideology. Political Psychology, 1025-1041.

[31] Carmines, E. G., \& D'Amico, N. J. (2015). The New Look in Political Ideology Research. Annual Review of Political Science, 205-216.

[32] Morton, R., Tyran, J.-R., \& Wengström, E. (2011). Income and Ideology: How Personality Traits, Cognitive Abilities, and Education Shape Political Attitudes. Copenhagen: Univ. of Copenhagen Dept. of Economics Discussion Paper No. 11-08.

[33] Amodio, D. M., Jost, J. T., Master, S. L., \& Yee, C. M. (2007). Neurocognitive correlates of liberalism and conservatism. Nature Neuroscience, 1246-7.

[34] Katz, E. (1957). The Two-Step Flow of Communication: An Up-To-Date Report on an Hypothesis. Public Opinion Quarterly, 61-78.

[35] Neubaum, G., \& Krämer, N. C. (2017). Opinion Climates in Social Media: Blending Mass and Interpersonal Communication. Human Communication Research, 464-476.

[36] Meade, A. W., \& Bartholomew, C. S. (2012). Identifying careless responses in survey data. Psychological Methods, 437-455.

[37] G. Pennycook, J. McPhetres, Y. Zhang and D. G. Rand, "Fighting COVID-19 misinformation on social media: Experimental evidence for a scalable accuracy nudge intervention," 2020. [Online]. Available: http://ide.mit.edu/publications/fighting-covid-19misinformation-social-media-experimentalevidence-scalable-accuracy. 